\title{
Measure to Succeed: How to Improve Employee Participation in Continuous Improvement
}

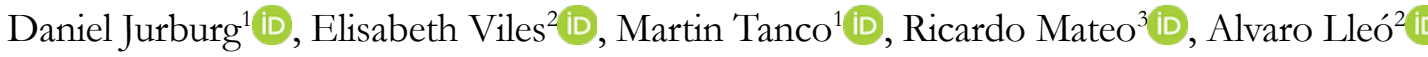 \\ ${ }^{1}$ Faculty of Engineering - Universidad de Montevideo (Uruguay) \\ ${ }^{2}$ Tecnun - University of Navarra (Spain) \\ ${ }^{3}$ School of Economics \& Business Administration, University of Navarra (Spain) \\ djurburg1@um.edu.uv, eviles@,tecnun.es,ntanco@um.edu.uy, rmateo@,unav.es, alleo@,tecnun.es
}

\section{Abstract:}

Purpose: Achieving employee participation in continuous improvement (CI) systems is considered as one of the success factors for the sustainability of those systems. Yet, it is also very difficult to obtain because of the interaction of many critical factors that affect employee participation. Therefore, finding ways of measuring all these critical factors can help practitioners manage the employee participation process accordingly.

Design/methodology/approach: Based upon the existing literature, this paper presents a 4-Phase ( 9 steps) diagnostic tool to measure the main determinants associated with the implementation of CI systems affecting employee participation in improvement activities.

Findings: The tool showed its usefulness to detect the main weaknesses and improvement opportunities for improving employee participation in CI through the application in two different cases.

Practical implications: This diagnostic tool could be particularly interesting for companies adopting CI and other excellence frameworks, which usually include a pillar related to people development inside the organization, but do not include tools to diagnose the state of this pillar. 
Originality/value: This diagnostic tool presents a user's perspective approach, ensuring that the weaknesses and improvement opportunities detected during the diagnose come directly from the users of the CI system, which in this case are the employees themselves. Given that the final objective is to identify reasons and problems hindering employee participation, adopting this user's perspective approach seem more relevant than adopting other more traditional approaches, based on gathering information from the CI system itself or from the CI managers.

Keywords: continuous improvement, employee participation, diagnostic tool

\section{Introduction}

Continuous improvement (CI) systems are some of the best strategies companies have to compete in nowadays increasingly complex business environment. These systems vary in some of the methodologies used, but all rely on one basic pillar, which is involving all employees into continuous and (usually) small-scale improvements of everyday activities along the whole set of processes inside the organization.

In particular, achieving a high degree of employee commitment and motivation has been regarded as one of the main critical success factor for CI implementation (García, Maldonado, Alvarado \& Rivera, 2014; Dahlgaard \& Dahlgaard-Park, 2006). Yet, at the same time, many authors regard this task as very difficult and enduring to achieve (Garcia-Lorenzo \& Prado, 2003; Rapp \& Eklund, 2007). One possible explanation for this could be to accept that employee participation depends on a very large set of factors that interrelate, converting the issue of employee participation a complex problem. In particular, various authors have proven relationships between employee participation or commitment with CI activities and many organizational and individual-level factors related to daily management, but all of them argued that more theoretical and empirical research on these possible relationships should be conducted (Tang, Chen, \& Wu, 2010; De Menezes, 2012; Garcia-Arca \& Prado-Prado, 2011; Lam, O’Donnel, \& Robertson, 2015; Lok, Hung, Walsh, Wang, \& Crawford, 2005).

In order to succeed in achieving a high degree of employee involvement in CI activities, managers should acknowledge the main factors associated with affecting employee motivation to participate in CI activities, finding ways to manage them accordingly. Once these factors are agreed, the first step towards effective management is finding good ways to measure them.

The importance of having good measures to manage the CI system has been covered in previous CI literature (Jaca, Viles, Mateo, \& Santos, 2012; Garcia-Sabater, Marin-Garcia \& Perello-Marin, 2012). However, some previous recent work reveal that, at least in Spain, there is a gap between what companies 
should do and what they really do in terms of using a holistic approach towards measuring all the relevant factors considered, especially when it comes to measuring the soft side of the improvement programs. In particular, a study conducted by Jaca et al. (2012) showed that less than $20 \%$ of surveyed companies had metrics to measure other intangible aspects of the system such as communication, teamwork promotion, participant recognition and managerial commitment. A more recent survey made to industrial companies in the Basque Country and Navarra regions (Jurburg, Viles, Tanco \& Mateo, 2016a), showed that less than $30 \%$ of the surveyed companies measure non-economic benefits and other soft-variables such as employees' satisfaction with CI participation.

In view of these findings, developing new ways of measuring employee determinants for CI participation in an effective and transparent way, is a topic worth researching. The objective of this paper is to present the practical application of a user's perspective diagnostic tool to measure the main organizational factors affecting employee participation (EP) in CI, based on a list of determinants of EP designed by Jurburg, Viles, Tanco \& Mateo (2016b). The tool was used in two case scenarios: a manufacturing plant and a public service organization.

A brief description of the determinants of EP considered for the study, the methodology used, and the results from these applications are shown next in this paper. This paper concludes with a discussion about the main results and the usefulness of this diagnostic tool to monitor and managed EP and its organizational determinants.

\section{Determinants of Employee Participation}

CI should be a people-focused system intended to engage everyone in continuously participating in improvement projects and activities. Yet this is a very enduring and demanding task for managers, one in which it is not easy to succeed. This has motivated several authors like Garcia et al. (2014), Garcia-Sabater et al. (2012), Dahlgaard-Park (2012) and Bateman (2005), to undertake research regarding the discovery of a series of CI enablers or success factors, all related to the functioning and participation of people inside the organization that could account for the success or failure of different CI initiatives. Although they provide many arguments for including these factors, they failed to provide a comprehensive but concrete list of items inside each of these factors that should be considered by managers in order to monitor EP in CI and its determinants.

Recently, Jurburg et al. (2016b) gathered all these information about CI enablers affecting EP, and through a Delphi study followed by an interpretive structural model (ISM), constructed a list of 52 items 
grouped into 13 different factors to measure EP in CI and its main determinants. Figure 1 shows the resulted model.

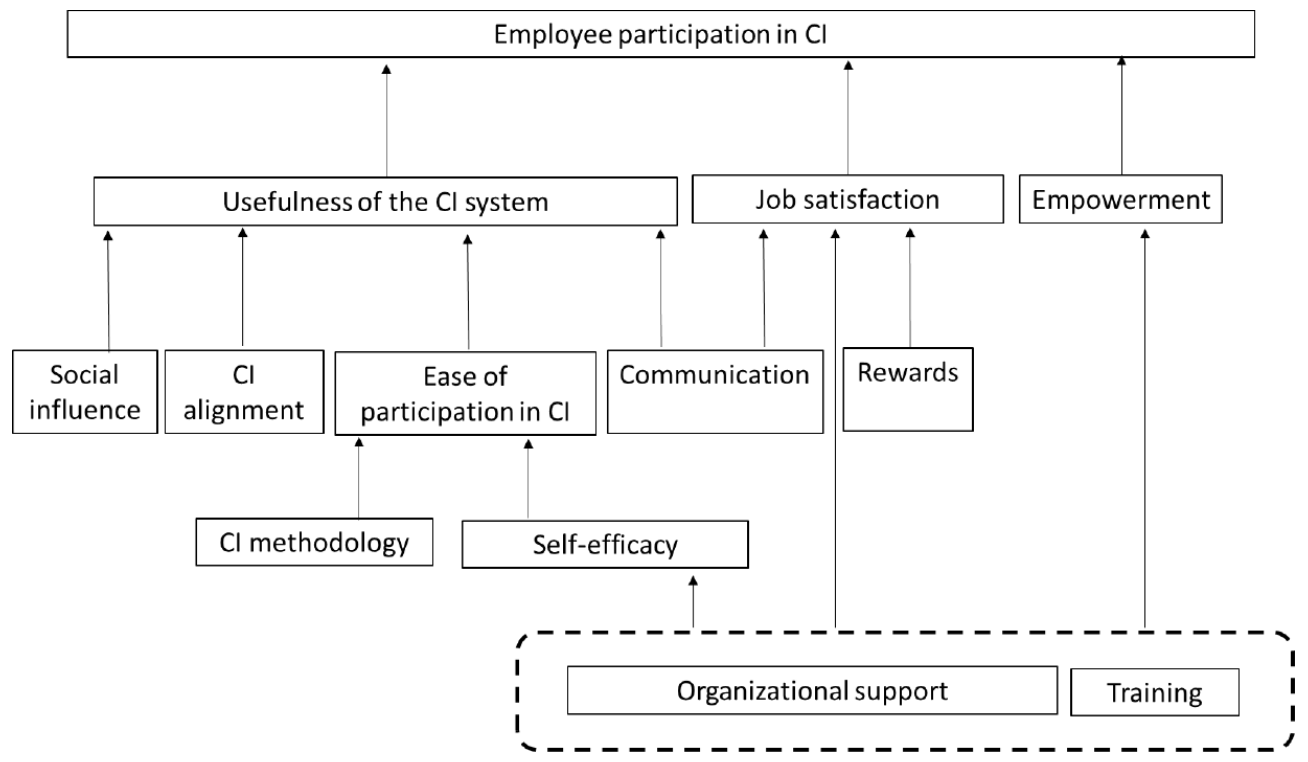

Figure 1. Comprehensive model for EP and its main determinants (Jurburg et al., 2016b)

\section{Methodology}

As stated in the introduction, the main objective of this paper is to present the practical application of a user's perspective diagnostic tool to measure the main organizational factors affecting EP in CI. The diagnostic tool is based on the application of a survey derived from the adaptation of the list of determinants of EP shown in Figure 1. The assessment of the company is completed by analysing the results from this questionnaire plus a discussion with the company's managers in order to gain further insights into the reality of the CI system and employee participation.

Figure 2 shows the phases and steps of this CIAM diagnostic methodology, which are described as following:

- Phase 1 - Understanding the company and its CI system

- Step 1: Conduct a meeting with the surveyed company's managers in order to have a first contact with their CI system. In particular, extract information about the characteristics of the CI system in place, level of employee participation, and managerial concerns about the CI system. 
- Step 2: Once the assessment is agreed, use the company's information to personalize the general version of the questionnaire to include the particularities of the company being studied.

- Phase 2-Designing the survey

- Step 3: Develop, in collaboration with the company's managers, a communication strategy to spread the word about the survey. This step is important in order to get employee buy-in.

- Step 4: Decide the way in which the survey is going to be administered. There are two options, either using internal resources from the company, or asking for external resources such as a research team. Here, it is also important to decide whether employees will be allowed to complete the survey within production hours, in their free-times or at home. Managers should also agree on whether the questionnaire will be delivered on paper or through a web-link.

- Phase 3 - Applying the survey

- Step 5: Conduct pilot tests to verify that the questionnaire is clear and simple enough to be completed by all intended employees. A verification of the length of the survey (in terms of minutes) should also be done to ensure that employees will have enough time to complete it in a proper way (having time to think about the questions and answer them honestly). This should be done by asking a random sample of employees from different functional levels to complete the survey before administering it to the whole population, and asking them for their comments and suggestions.

- Step 6: Administer the survey to all employees within the company, or to a statistically representative sample. Special efforts should be made in order to ensure that all employees have the opportunity to answer the questionnaire. Anonymity should also be assured to all employees, in order to help them respond without external pressures. It is important to assign dedicate personal to this task. It is also recommended to have a minimum desired response level. This will help the dedicated personnel to take corrective actions during the administration of the survey in order to achieve this target.

- Phase 4 - Analyse results

- Step 7: Collect all the answers and analyse the information. It involves analysing strengths and weaknesses of the CI system, looking for possible reasons why each factor could be perceived as strong or weak, and looking at the employees' reasons for not participating and employees' comments about possible improvement opportunities for the CI system. 
- Step 8: Discuss results with the company's managers. Help them reflect about the results, and whether they were expected or not by the company.

- Step 9: In view of the findings and the discussion, make a final report with main results and an action plan with recommendations for the company as to how to improve employee participation in CI.

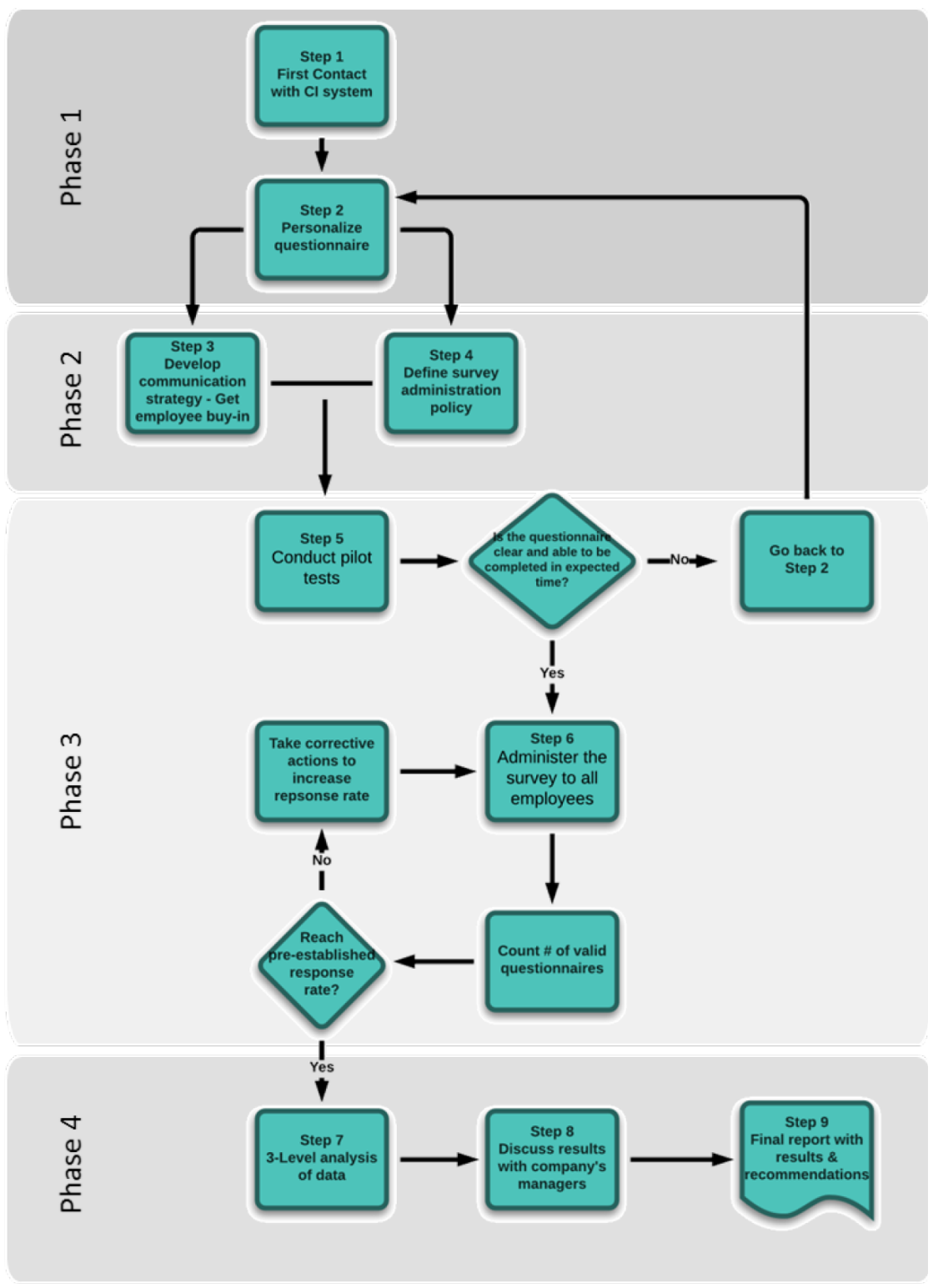

Figure 2. CIAM 9-step diagnostic methodology

Next, the main characteristics of the general survey (Step 2) are explained with more detail. Afterwards, two examples of the use of the 9-step CIAM diagnostic methodology are explained. Finally, some conclusions about the use of this methodology are expressed. 


\subsection{Survey Characteristics}

As mentioned earlier, most of the items included in the survey were adapted from the model shown in Figure 1.

The tool is applied from the perspective of the users of the CI system, in this case the employees themselves. The final version contained 55 items grouped into 14 factors (the EP factor was divided in 'employee intention to participate' and 'employee participation'). The recommendation is that all items are measured using a 5-point Likert-scale, being 1 'totally disagree' and 5 'totally agree' with the given statement. This questionnaire was empirically validated to assure good psychometric properties by Viles, Jurburg, Lleo, Tanco \& Mateo (2015).

Furthermore, some characterization variables must be included, depending on the interests of the surveyed organizations. Typical variables include: Job type (e.g. administrative/managerial and shop-floor), age, gender, section within the company (this is especially interesting when different parts of the organization have different working habits), years working for the company (this could be interesting for older companies that have applied different CI methods during the years), level of employee CI participation in the past. This is particularly important to enable the subsequent analysis (after survey administration) to include a comparison of different groups of interest expressed by the company's managers, improving the conclusions derived from the data obtained.

Finally, two open-ended questions were added, to collect employees' reasons for not participating in the CI system, as well as their ideas about how to improve the CI system to make it more attractive for employees to participate.

Anonymity was ensured during all the surveys. This is essential to allow employees to answer honestly, without feeling anxious or worried about being observed or measured by their supervisors. 


\section{Cases Selected}

Two different cases were selected to apply this diagnostic tool: one private manufacturing company and one public city hall. One of the reason for choosing these different cases is to show the versatility of the diagnostic tool under different scenarios.

\subsection{CASE 1: Private Manufacturing Plant}

\subsubsection{Phase 1: Understanding the Company and its CI System}

The first company selected for this study is a manufacturing and assembly plant. It is part of a multinational group that is very committed to quality and excellence both in products and processes. At the time of the survey, the plant employed around 800 people (counting both white and blue collar workers) distributed across three shifts per day.

The company's CI system consists of two different established employee participation processes: participation in CI activities or projects that are mainly connected with manufacturing problems, and participation in a formal suggestion process. Both processes have been functioning for many years, with moderately good results. One of the reasons argued by the company to conduct the survey was to better understand what was necessary to increase employees' motivation to participate in the CI system.

Because they had recently merged two divisions into one single facility, and these two divisions had different maturity stages in terms of CI working habits, they were interested in seeing how these differences were perceived by their employees.

This is why they insisted in including as the main characterization variable the division of the employees surveyed (we will call them Sector A and Sector B). Other characterization variables included were age, years within the company, level of participation during 2014 (previous year), and job position (shop floor or managerial/administrative level). The last part of personalizing the questionnaire consisted of including one sentence at the beginning, explaining the objective of the survey and an explanation of what should be understood by employees as improvement activities (in this case the suggestion system which had a specific name within the company and the improvement teams). 


\subsubsection{Phase 2: Designing the Survey}

All the organization and planning of the survey was conducted between the research team and the industrial plant manager. The survey was administered during 2015. In this case the target population were all employees within the factory including: managers, middle managers, and line-workers.

During these meetings, the research team emphasized in the importance of having what we could call 'employee buy-in', meaning that employees really understand the importance that achieving a high degree of participation in the survey had on the survey's results, therefore getting employees' commitment to responding. To do this, the research team developed a communication strategy which consisted first of sending a letter explaining the project to the company's union. After their approval, a second wave of communication began, this time focused on reaching all employees. This strategy consisted of hanging posters announcing the survey in all the main common areas of the factory one week before the survey, e-mailing and briefing all middle-managers about the importance of getting their teams answering the survey, and asking them to cascade these information down the chain of command. Finally, the research team went to the factory one day in advance, stood at the entrance of the factory during all the changes of shift, and brief all employees face-to-face as they enter for work (also giving them a short leaflet which replicate the information in the posters). As another way of getting this intended 'buy-in', the company also offered a raffle between all the employees participating in the survey results, the research team attached a separate ticket to the survey sheet, so that the ticket was thrown into one box and the survey sheet in another different box.

After agreeing on the activities to get employee buy-in, the research team and the industrial manager decided about the survey administration strategy. In this case, the survey was administered in paper, and the pre-established target was at least 300 answers (based on recommendations of the company given previous response rates for other similar surveys). To achieve this target, members of the research team were at the entrance of the company at every change of shift in order to give empty questionnaires to all employees on their way in to the factory, and collect all completed questionnaires of employees leaving for their homes. Also, members of the research went personally through all the company's offices to distribute empty questionnaires to administrative and managerial-level employees. Furthermore, members of the research team were present at the factory (especially during breaks) to assist employees with any doubt, and encourage them to answer the survey during their free time. 


\subsubsection{Phase 3: Pilot Test and Survey Administration}

After designing the survey process for the company, one pilot test was conducted. Two employees, from different functional levels and sections within the company, were selected. They were explained the project and asked to complete the questionnaire. They were then asked to give their feedback about the length of the survey and the clarity of the concepts included in the survey. After they approved that the survey was clear enough and that it was able to complete it in an adequate time (about 10 minutes), the survey was ready to be administered. At the end of the administration process which lasted two full days, a total of 308 answers were collected, meaning a 40 percent response rate.

\subsection{Case 2: Public Service Organization}

\subsubsection{Phase 1: Understanding the Company and its CI System}

The second organization selected, was a city hall, located in the Basque Country region. The city hall has recently started to work with CI systems focused on improving service quality. At the time of the survey, the city hall employed around 300 people between administrative and street brigades.

The main interest for conducting this survey was that the city hall was starting in their CI journey, and therefore, wanted to see what people inside the organization had to say about the implementation of the CI activities already established.

Because they had recently started with improvement activities, they were interested in seeing whether employees that had already participated in the system perceived the different aspects of the CI system differently than how the non-participant employees perceived them. This is why they included some questions about participation in the last year as their main characterization variable. They also included other characterization variables to the survey such as age, years within the company, job position (office or street brigade), and area of work. The last part of personalizing the questionnaire consisted of including one sentence at the beginning, explaining the objective of the survey and an explanation of what employees understand as improvement activities. In this case, this explanation included a list of activities conducted inside the city hall as part of their quality improvement system focused on improving quality of service. Given that the city hall is used to working in two languages, Spanish and Euskera (native language from the Basque country), the list of improvement activities appeared in both languages. 


\subsubsection{Phase 2: Designing the Survey}

All the organization and planning of the survey was conducted between the research team, the mayoress and the quality technician. This application was also backed up by involving a consultancy firm already working with the city hall. Because of this, one senior consultant was included in the research decision-making group. This survey was conducted during 2015 and the target population were all employees including: administrative and street brigades.

The communication strategy was conducted by hanging posters announcing the survey in all the main common areas, e-mailing all the office-based employees, and organizing two face-to-face sessions to explain the survey (one for office-based employees and one for field-based employees or street brigades).

In this case, two different methods were used to administer the survey (Step 4). Paper and on-line forms (through web links) were offered to all employees in the office. Paper versions were offered to employees working in the street. A special day and time was agreed, and communicated to employees in the street, to answer the survey at the city hall facilities. In addition, given that the city hall usually works both in Spanish and Euskera, the questionnaire was translated and offered in both languages. The process included two specific days (non-consecutives) in which office and street brigades' employees were invited to answer the survey in paper. Also, for all the office-based employees, who had access to a computer during working hours, a one-week extra period was provided in order for them to complete the survey at the web link provided.

\subsubsection{Phase 3: Pilot Test and Survey Administration}

In this case, the pilot test were conducted with the senior consultant and with our counterpart in the city hall. In particular, special focus was taken during this pilot to ensure that the meaning in Euskera was as similar as possible to the meaning of the questionnaire in Spanish. A time length of 10 minutes was also considered. Finally, given that in this case a web-link was also generated, further pilot tests were made to ensure that the link was working properly and that the answers were recorded. After they all approved that the survey was clear enough, that the meanings in both languages were the same, and that the link was working properly, the survey was ready to be administered.

At the end of the administration process, 62 answers were collected, meaning around 20 percent response rate. 


\section{Phase 4: Results}

First, general results for both samples will be shown. In particular, a bar chart with the scores for all the factors included in the survey will be displayed in Figure 3 and Figure 4. The x-axis intersects the y-axis in the middle of the scale $(y=3)$. This allows to see high scores above the $\mathrm{x}$-axis and low scores below the $\mathrm{x}$-axis, facilitating the detection of strengths and weaknesses of the CI system according to the perception of the employees.

Second, the results from the survey were analysed according to the main characterization variable selected by each organization as the most relevant. In the industrial case, results in Figure 5 shows the comparison between employees from Sector $A(N=223)$ and employees from Sector $B(N=40)$, being Sector $B$ the one with more advanced CI working habits. On the other hand, Figure 6 shows the comparison, for the city hall case, between the mean perceptions of employees that have participated both in projects and suggestions during $2014(\mathrm{~N}=31)$, and employees who have not participated nor in projects nor through the submission of improvement suggestions during $2014(\mathrm{~N}=22)$. The results are shown in the form of radar charts.

\section{5,0}

4,5

4,0

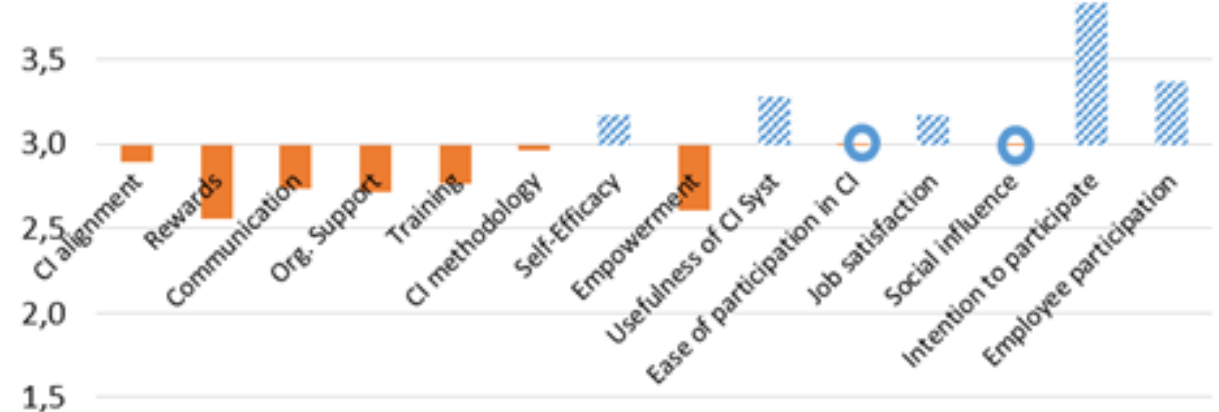

1,0

Figure 3. Industrial case: general mean perceptions (solid filled rings are inserted when the score of the factor is exactly 3 for better visualization) 


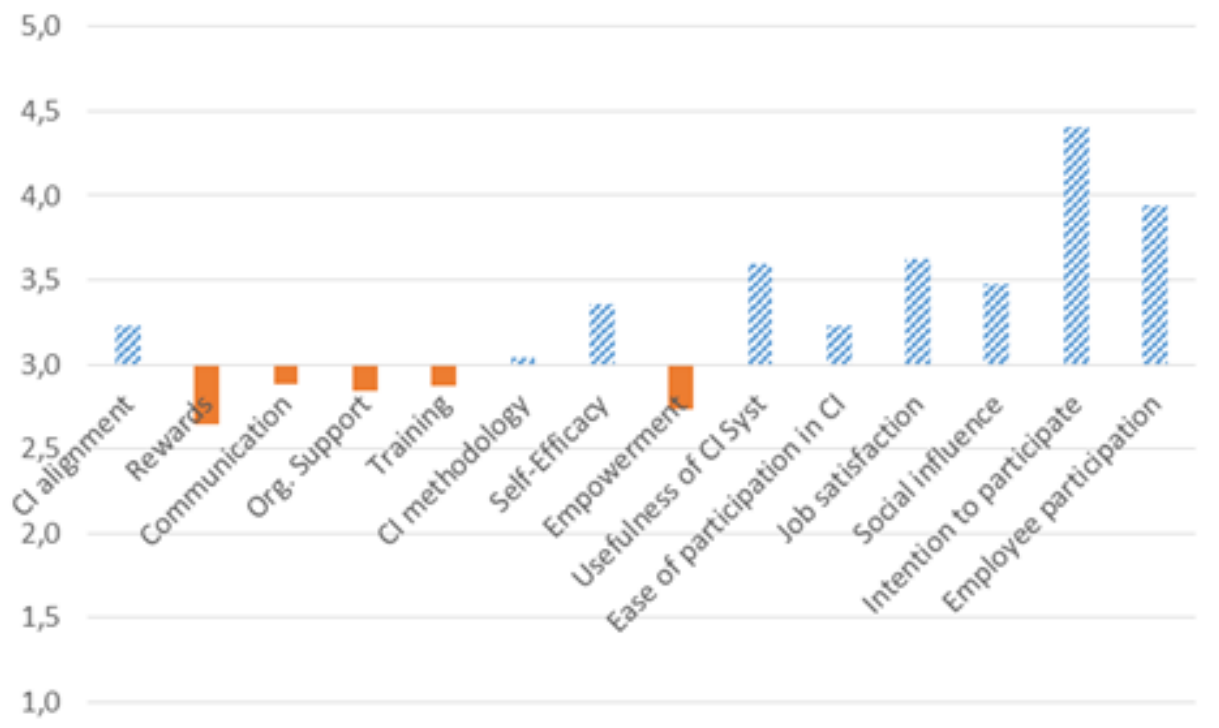

Figure 4. Service case: general mean perceptions

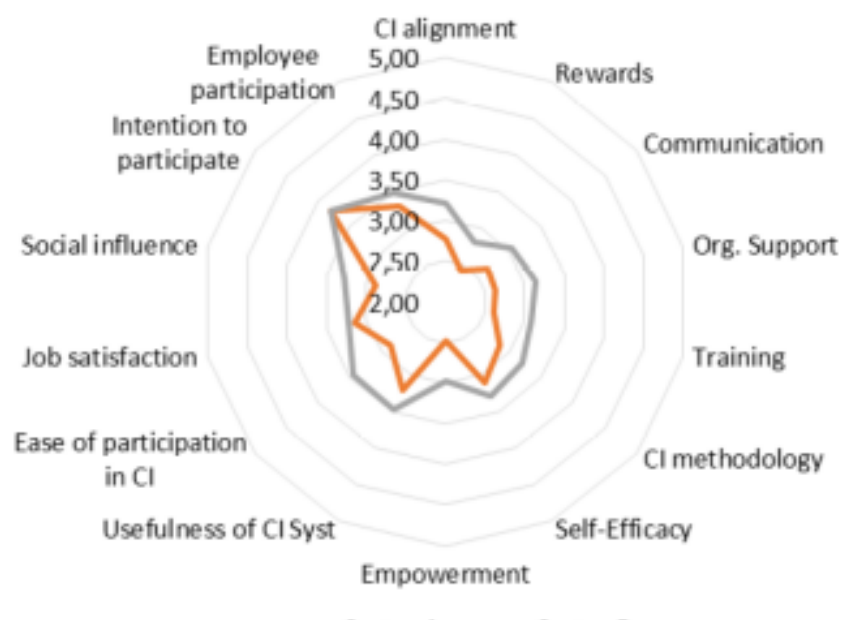

Figure 5. Industrial case: comparison between Sectors 


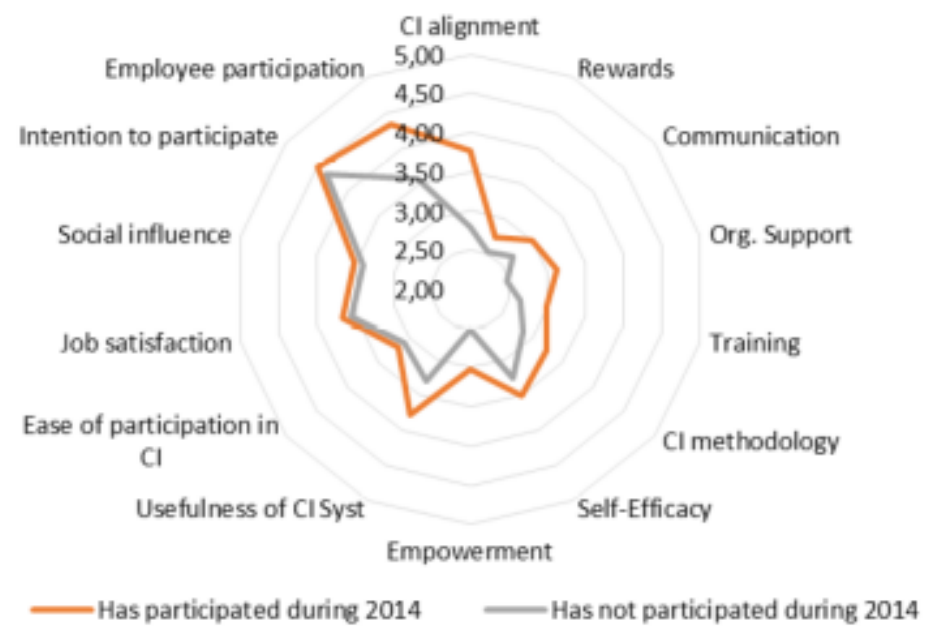

Figure 6. Service case: comparison between participants and non-participants

Finally, based on the answers to the two final open-ended questions about improvement ideas for the CI system and about problems hindering EP, the answers were analyzed and grouped according to the ideas expressed. A summary of the top 3 problems and top 3 ideas for each of the studied cases are presented in Table 1 and Table 2.

\begin{tabular}{|l|r|}
\hline Problems hindering EP & \# Opinions \\
\hline Lack of information/knowledge about the CI system & 21 \\
\hline I do not feel considered or required by the company & 20 \\
\hline Lack of Available Time & \# Opinions \\
\hline Improvement ideas & 15 \\
\hline Have more information about the CI system and its activities & 15 \\
\hline Better rewards and incentives & 14 \\
\hline More motivation from the Company to participate and improve & \\
\hline
\end{tabular}

Table 1. Industrial case: Top 3 improvement ideas and problems hindering EP

\begin{tabular}{|l|r|}
\hline Problems hindering EP & \# Opinions \\
\hline Lack of information/knowledge about the CI system & 5 \\
\hline I do not feel considered or required by the company & 3 \\
\hline Lack of specific proposals or projects to participate in & \# Opinions \\
\hline Improvement ideas & 6 \\
\hline Have more information about the CI system and its activities & 6 \\
\hline More specific CI training for supervisors and subordinates & 6 \\
\hline $\begin{array}{l}\text { Listen more to workers improvement ideas and problems, who are the ones } \\
\text { that know best about the day-to-day operations on the workplace }\end{array}$ & \\
\hline
\end{tabular}

Table 2. Service case: Top 3 improvement ideas and problems hindering EP 


\section{Discussion}

In the industrial case, the main weaknesses detected were: CI alignment, Rewards, Communication, Organizational Support, Training, CI methodology, Self-Efficacy and Empowerment. Reasons for strengthening these factors as a way of achieving CI success are well documented throughout CI literature as seen in the previous review section.

When looking at the industrial case results, it is interesting to see these weaknesses appearing in a company with a structured and formal CI system in place. Yet, when debriefing the results with the industrial manager of the company, he validated our results arguing that the company had the systems but they were not accordingly promoted and embedded into daily management and work. This is a proof of what other authors have stated about implementing a formal methodology being a necessary but not sufficient condition for CI success (Kaynak 2003). It has been proven that it is important to support and leverage the technical methodology with all the other soft and intangible human factors already discussed in order to succeed in the CI journey (Yang \& Yang, 2013). Another interesting point of the analysis in favor of the benefits of the diagnostic tool is the fact that the tool was able to detect differences between groups adequately. In particular, results show that employees in Sector B, which was the one with the most advanced CI working habits perceived the different aspects of the CI system in a better way than those employees working in Sector A.

Furthermore, looking at the arguments mentioned by the employees about why they were not motivated to participate, some interesting findings arise. For example, among the top three most mentioned, we see that employees feel that they lack of information and knowledge about the CI system, they do not feel considered or required by the company and they feel that the company does not provide them with enough time to participate in the CI system. This is highly valuable information for managers, since they are feelings coming directly from the users of the system. Therefore, the company should focus on increasing employees' awareness about the existence of a CI system and the different activities available, they should try to motivate them by acknowledging the key role employees play in this process and they should improve their working practices and habits to include time for CI. Other main ideas for improving the CI system to make it more attractive for workers to participate, collected from the employees' feelings, relate to feeling more valued (better recognitions and fair treatment) and improving the relationship and communication between supervisors and their employees. Once again, the company should understand the active role that employees plays in the CI system, and should therefore make and extra effort to boost cohesion and collaboration along the whole company, creating a harmonic atmosphere in which CI can develop properly. 
In the city hall case, the main weaknesses perceived by the employees were: Rewards, Communication, Organizational Support, Training, CI methodology, Self-Efficacy, and Empowerment. Because this is an institution starting in the CI journey, it is essential that these weaknesses and the improvement opportunities are addresses accordingly. Results show that employees who have participated in the improvement system have a better perception of the critical factors involved in the CI system than those who have not yet participated. A possible argument for these results could be the employee resistance to change, something highlighted in the literature as one of the main barriers to CI implementation (García, Rivera \& Alvarado, 2013), and how that resistance can make employees adopt a negative prejudice. In that sense, one common good practice often used in CI is to make the 'believers' (those who have already participated in the system) teach using their own example to the rest of the employees and help convince them to join in the CI process.

When looking at the main problems hindering employee participation in the city hall, employees feel that they do not have enough information and knowledge about the CI system, and that they do not feel they have real opportunities to participate. Some of the main ideas for improving the system included: having more information, more specific CI training for both supervisors and subordinates, to pay more attention to improvement ideas and problems made by employees (who are the ones that know best about the dayto-day operations on the workplace), assign more economic resources to the system, and improve communication between employees and supervisors. As with the industrial case, ideas related to understanding the real value of employees within the CI system, giving real opportunities to participate and create a better environment in which CI can develop arise. It is important that managers understand these current problems perceived and take into consideration employees' feelings and ideas on how to make them more motivated to involve and participate in the CI system.

These two applications are, as usually happen with most of the research conducted, subject to some limitations. In our opinion, one of the main limitations is that participation in the survey was voluntary in both cases. In particular, in the city hall we could only achieve a $20 \%$ response rate. This could partially explain why the results in terms of employee intention to participate and employee participation was in general moderate-high in both cases. It is therefore possible that these two variables have a lower score for the entire population. Nevertheless, the scores of the sampled groups in both cases are still very interesting to analyse their perception of the system, mainly because according to the same bias, they represent a perception based on their own experience. Furthermore, the arguments about current elements from the system hindering employee participation and the main improvement opportunities detected could make the whole organization improve. 


\section{Conclusions}

After looking at both set of results, and after discussing the results with the people responsible for the CI systems in both cases and verifying that the results obtained reflected the reality of both places, we can conclude that using this diagnostic tool can help managers to detect some of the main weaknesses and barriers hindering employees from participating more actively in the CI process. It also allows to detect many improvement opportunities as to how the CI system should be improved in order for employees to feel more interested and motivated to participate. By adopting a user approach, managers will be more effective in the decisions they take in order to improve employee participation and commitment. Since employee motivation and commitment is an essential success factor in all improvement systems, this tool offers great advantages for any manager wishing to improve the different aspects of the CI system responsible for motivating employee participation in these activities.

To conclude, this paper presents the application of an innovative diagnostic tool to measure the main organizational determinants associated with the implementation of CI systems and responsible for affecting EP in CI activities. The tool adopts a user perspective approach, guaranteeing that the weaknesses and improvement opportunities detected come directly from the users of the CI system themselves. Developing this type of diagnostic tools could be particularly interesting for companies adopting excellence frameworks, which they usually include a whole chapter related to people development inside the organization, but no tools are offered to diagnose this issue. These kind of developments also serve to translate all the academic knowledge about CI into useful and practical tools that can be used by practitioners to actually manage the different aspects of the CI systems, in this case EP. This effort of taking academic knowledge and converting it into useful and practical tools for practitioners is a necessary exercise that needs to be done in order to help the organizations advance towards business excellence and innovation.

\section{References}

Bateman, N.A. (2005). Sustainability the Elusive Element of Process Improvement. International Journal of Operations \& Production Management, 25(3), 261-276. https:/doi.org/10.1108/01443570510581862

Dahlgaard, J.J., \& Dahlgaard-Park, S.M. (2006). Lean production, six sigma quality, TQM and company culture. The TQM Magazine, 18(3), 263-281. https:/doi.org/10.1108/09544780610659998

Dahlgaard-Park, S.M. (2012). Core values - the entrance to human satisfaction and commitment. Total Quality Management \& Business Excellence, 23(2), 125-140. https:/doi.org/10.1080/14783363.2012.655067 
De Menezes, L.M. (2012). Job satisfaction and quality management: an empirical analysis. International Journal of Operations \& Production Management, 32(3), 308-328. https:/doi.org/10.1108/01443571211212592

García, J.L, Rivera, D.G., \& Alvarado, A. (2013). Critical success factors for Kaizen implementation in manufacturing industries in Mexico. International Journal Advanced Manufacturing Technology, 68, 537-545. https:/doi.org/10.1007/s00170-013-4750-2

García, J.L., Maldonado, A.A., Alvarado, A., \& Rivera, D.G. (2014). Human critical success factors for kaizen and its impacts in industrial performance. International Journal Advanced Manufacturing Technology, 70, 2187-2198. https:/doi.org/10.1007/s00170-013-5445-4

García-Arca, J., \& Prado-Prado, J.C. (2011). Systematic Personnel Participation for Logistics Improvement: A Case Study. Human Factors and Ergonomics in Manufacturing \& Service Industries, 21(2), 209-223. https:/doi.org/10.1002/hfm.20246

García-Lorenzo, A. \& Prado, J.C. (2003). Employee participation systems in Spain. Past, present and future. Total Quality Management and Business Excellence, 14(1), 15-24. https:/doi.org/10.1080/14783360309704

Garcia-Sabater, J.J., Marin-Garcia, J.A., \& Perello-Marin, M.R. (2012). Is implementation of continuous improvement possible? An evolutionary model of enablers and inhibitors. Human Factors and Ergonomics in Manufacturing \& Service Industries, 22, 99-112. https:/doi.org/10.1002/hfm.20262

Jaca, C., Viles, E., Mateo, R., \& Santos, J. (2012). Components of sustainable improvement systems: theory and practice. The TQM Journal, 24(2), 142-154. https:/doi.org/10.1108/17542731211215080

Jurburg, D., Viles E., Tanco, M., \& Mateo, R. (2016a). Continuous Improvement Leaders, Followers and Laggards: Understanding System Sustainability. Total Quality Management \& Business Excellence. In press, https:/doi.org/10.1080/14783363.2016.1240610

Jurburg, D., Viles, E., Tanco, M., \& Mateo, R. (2016b) What motivates employees to participate in continuous improvement activities?. Total Quality Management \& Business Excellence. In press. https:/doi.org/10.1080/14783363.2016.1150170

Kaynak, H. (2003). The relationship between total quality management practices and their effects on firm performance. Journal of Operations Management, 21, 405-435. https:/doi.org/10.1016/S0272-6963(03)00004-4

Lam, M., O’Donnell, M., \& Robertson, D. (2015). Achieving employee commitment for continuous improvement initiatives. International Journal of Operations \& Production Management, 35(2), 201-215. https:/doi.org/10.1108/IJOPM-03-2013-0134 
Lok, P., Hung, R.Y., Walsh, P., Wang, P., \& Crawford, J. (2005). An integrative framework for measuring the extent to which organizational variables influence the success of process improvement programmes. Journal of Management Studies, 42, 1357-1381. https:/doi.org/10.1111/j.1467-6486.2005.00547.x

Rapp, C., \& Eklund, J. (2007). Sustainable development of a suggestion system: Factors influencing improvement activities in a confectionary company. Human Factors and Ergonomics in Manufacturing \& Service Industries, 17(1), 79-94. https:/doi.org/10.1002/hfm.20064

Tang, Z., Chen, X., \& Wu, Z. (2010). Using behavior theory to investigate individual-level determinants of employee involvement in TQM. Total Quality Management \& Business Excellence, 21(12), 1231-1260. https:/doi.org/10.1080/14783363.2010.530794

Viles, E., Jurburg, D., Lleo, A., Tanco, M., \& Mateo, R. (2015). Design and Validation of a questionnaire for analyzing the employees participation in continuous improvement. Dyna Management, 3(1), 1-15. http://dx.doi.org/10.6036/MN7823

Yang, C.C., \& Yang, K.J. (2013). An Integrated Model of the Toyota Production System with Total Quality Management and People Factors. Human Factors and Ergonomics in Manufacturing \& Service Industries, 23(5), 450-461. https:/doi.org/10.1002/hfm.20335

Article's contents are provided on an Attribution-Non Commercial 3.0 Creative commons license. Readers are allowed to copy, distribute and communicate article's contents, provided the author's and Journal of Industrial Engineering and Management's names are included. It must not be used for commercial purposes. To see the complete license contents, please visit http://creativecommons.org/licenses/by-nc/3.0/. 